\title{
Outcome after resection of Adrenocortical Carcinoma liver metastases: a retrospective study
}

\author{
Johannes Baur ${ }^{1 *}$ (D), Tjark-Ole Büntemeyer ${ }^{1}$, Felix Megerle ${ }^{2}$, Timo Deutschbein², Christine Spitzweg ${ }^{3}$, Marcus Quinkler $^{4}$, \\ Peter Nawroth ${ }^{5}$, Matthias Kroiss ${ }^{2,6}$, Christoph-Thomas Germer ${ }^{1}$, Martin Fassnacht ${ }^{2,6}$, Ulrich Steger ${ }^{1}$ on behalf of the \\ German Adrenocortical Carcinoma Study Group
}

\begin{abstract}
Background: Metastatic Adrenocortical Carcinoma (ACC) is a rare malignancy with a poor 5-year-survival rate $(<15 \%)$. A surgical approach is recommended in selected patients if complete resection of distant metastasis can be achieved. To date there are only limited data on the outcome after surgical resection of hepatic metastases of ACC.

Methods: A retrospective analysis of the German Adrenocortical Carcinoma Registry was conducted. Patients with liver metastases of ACC but without extrahepatic metastases or incomplete tumour resection were included.

Results: Seventy-seven patients fulfilled these criteria. Forty-three patients underwent resection of liver metastases of ACC. Complete tumour resection (R0) could be achieved in 30 (69.8\%). Median overall survival after liver resection was 76.1 months in comparison to 10.1 months in the 34 remaining patients with unresected liver metastases $(p<0.001)$. However, disease free survival after liver resection was only 9.1 months. Neither resection status (R0/R1) nor extent of liver resection were significant predictive factors for overall survival. Patients with a time interval to the first metastasis/ recurrence (TTFR) of greater than 12 months or solitary liver metastases showed significantly prolonged survival.
\end{abstract}

Conclusions: Liver resection in the case of ACC liver metastases can achieve long term survival with a median overall survival of more than 5 years, but disease free survival is short despite metastasectomy. Time to recurrence and single versus multiple metastases are predictive factors for the outcome.

Keywords: Adrenocortical carcinoma, Liver resection, Retrospective study, Prognosis, Survival analysis

\section{Background}

Adrenocortical Carcinoma (ACC) is a rare malignancy with an annual incidence of 0.7-2.0 cases per million population [1] with a poor prognosis [2-4]. Treatment strongly depends on tumour staging classification suggested by the European Network for Study of Adrenal Tumours (ENSAT) [5]. Here, primary tumours are classified into four groups (I-IV). ENSAT stage I and II include $\mathrm{T} 1$ and $\mathrm{T} 2$ primary ACC tumours without lymphatic involvement or distant metastases. Locally advanced tumours or ACC with lymphatic metastases but without distant spread are classified as ENSAT stage III.

\footnotetext{
* Correspondence: baur_j@ukw.de

1 Department of General, Visceral, Vascular and Pediatric Surgery, University

Hospital, University of Wuerzburg, Wuerzburg, Germany

Full list of author information is available at the end of the article
}

In these tumour stages, complete resection of primary tumour as well as regional lymphadenectomy with adjuvant mitotane therapy is recommended even if multivisceral resection is required $[2,6]$. Here, disease-specific 5 -year-survival rates of $82 \%, 61 \%$ and $13 \%$ for stage I, II and III are reported [5].

Metastatic (ENSAT stage IV) and recurrent ACC disease exhibit poor 5-survival rates of less than 15\% [7]. Nevertheless, if complete resection of distant metastases or recurrent tumour can be achieved, a surgical approach is recommended [ 7,8$]$ In a series of 154 patients analysed after first recurrence, complete resection of recurrent disease led to a median overall survival of 88 months, when R0 status was achieved, compared to 11 months in cases in whom surgery was not possible [9]. Similar results were seen in a recent series from France with 59 patients [10]. In the case of 
metastatic disease of ACC, the liver is one of the most involved organs beside the lung. In contrast to patients with isolated liver metastases (LM) of colorectal origin, in which surgical resection is recommended due to a 5-year overall survival rate of about $42 \%$ after first liver resection [11], there is as yet only limited data about the value of liver resection for non-colorectal, non-neuroendocrine metastases of other infrequent primary tumours such as ACC [12].

In the present study, we report on a retrospective analysis with a high case load using the German Adrenocortical Carcinoma Registry and focusing on a more homogeneous group of patients with resected and non-resected isolated liver metastases without extrahepatic manifestation of ACC origin to proof the value of liver resection for ACC LM.

\section{Methods}

\section{Data source}

The German Adrenocortical Carcinoma Registry, which was established in 2003 [13], was used for analysis. Patients having diagnosis of liver metastases from Adrenocortical carcinoma until the end of 2015 were involved in this study, and data of 1031 patients could be included. Clinical data was collected by trained medical personnel using structured evaluation forms containing comprehensive information on diagnostic procedures, surgical outcomes, and follow-up. The German Adrenocortical Carcinoma Registry was approved by the ethics committee at the University of Wuerzburg, and patients gave written informed consent.

\section{Patient selection}

From the registry, a total of 306 patients with ACC liver metastases (29.7\%) were identified. Of those, 219 patients were excluded, while 77 patients, who were at least 18 years of age, met the inclusion criteria of ACC liver metastases without extrahepatic metastatic disease at the time of diagnosis and without incomplete resection (R2 including debulking) (Fig.1).

Of the patients included in the study, 43 patients had undergone radical liver resection under curative intention between 1985 and 2015. The histologic diagnosis for each patient was made by the local pathologist. The remaining 34 patients with isolated ACC liver metastases had not undergone liver resection. Reasons for non-surgical treatment were rarely recorded. Reasons for this could be missing interdisciplinary tumour conferences in former times, the multicentre setting or a limited performance status as a reason for patients not being eligible for liver resection. To consider possible inhomogeneities characteristics like patient age at diagnosis of metastases, sex, side of primary tumour, diameter of the primary tumour, hormone status of the primary, the appearance of liver metastases (simultaneous or secondary), number of liver metastases, the extent of the surgical procedure and adjuvant therapies like mitotane were obtained from the registry and in the most cases of the selected patients directly by review the medical records. All patients were followed up on a regular basis (usually every 3 months). Therefore, a complete analysis of overall and disease free survival was possible.

\section{Statistical analysis}

Statistical analysis between the groups was carried out by using $\mathrm{X}^{2}$ test for categorical endpoints. A t-test was used for continuous endpoints. Survival analysis was

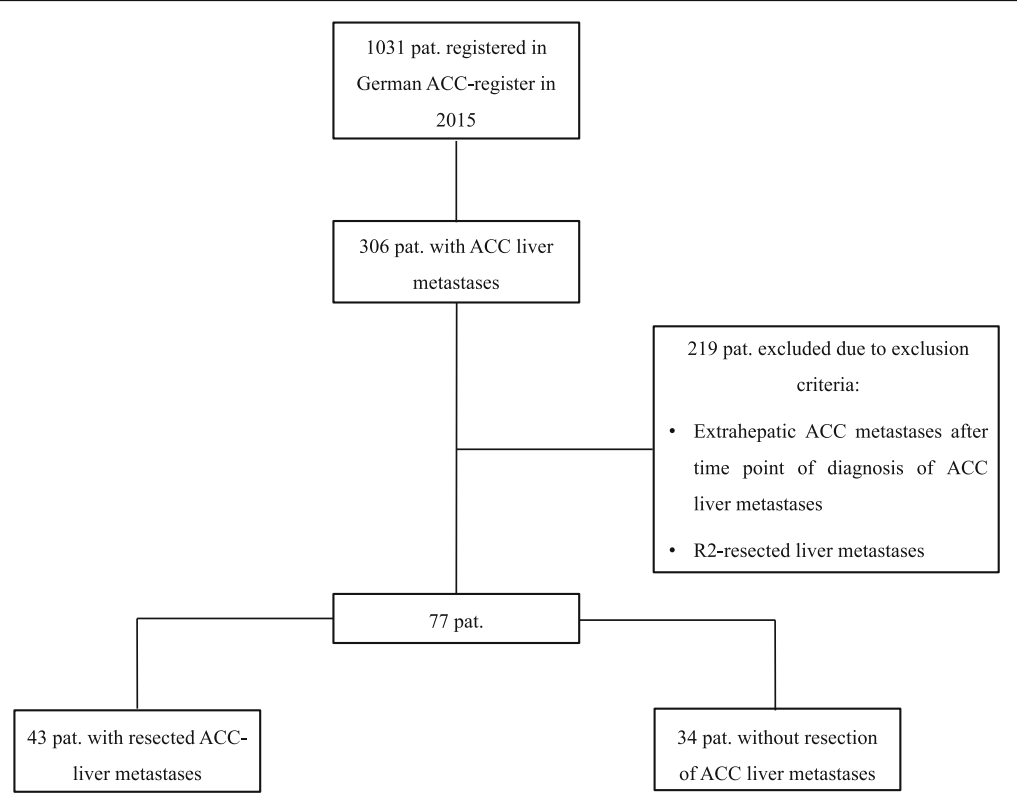

Fig. 1 Flow chart of the ACC registry patients and the selection process for patients with liver metastases and no extrahepatic manifestation 
performed using the Kaplan-Meier method and log rank test. A univariate analysis for relevant prognostic factors of overall and disease-free survival was performed using the Cox proportional hazards model. All factors that showed a trend in overall and disease-free survival in the univariate analysis $(p<0.1)$ were further investigated in a multivariate analysis. $P$-values $<0.05$ were considered statistically significant.

\section{Results}

\section{Patient characteristics}

Until 2015, 77 patients with liver metastases of ACC but without extrahepatic manifestation at the time of first appearance of the liver metastases were identified from the registry. Mean age at diagnosis of metastases was 49.8 years. There was a significant difference in the mean age at diagnosis between the group that underwent liver resection (46.0 years) and the nonsurgical group (54.7 years) (Table 1). The primary tumour was equally distributed on both sides. However, liver resection was performed more frequently, when the primary was localized on the right side (60.5\%). The number of patients with a primary tumour size of $>10 \mathrm{~cm}$ was significantly higher in the non-resection group (82.4\%) compared to the surgical group (55.8\%). In both groups, around $50 \%$ of the carcinomas were hormone-secreting. However, there was a high percentage of patients with unknown hormone status in the non-resection group

Table 1 Basic patients' characteristics

\begin{tabular}{|c|c|c|c|c|c|c|c|}
\hline & \multicolumn{2}{|c|}{ overall } & \multicolumn{2}{|c|}{ Liver resection } & \multicolumn{2}{|c|}{ no Liver resection } & \multirow[t]{2}{*}{$p$-value } \\
\hline & $\mathrm{n}$ & (\%) & $\mathrm{n}$ & $(\%)$ & $\mathrm{n}$ & $(\%)$ & \\
\hline \multicolumn{8}{|l|}{ Patiens } \\
\hline overall & 77 & & 43 & & 34 & & \\
\hline female & 56 & $(72.7 \%)$ & 30 & $(69.8 \%)$ & 26 & $(76.5 \%)$ & 0.512 \\
\hline Mean age at first diagnosis [y] & 49.5 & & 45.5 & & 54.5 & & 0.016 \\
\hline Mean age at diagnosis of liver metastases [y] & 49.8 & & 46.0 & & 54.7 & & 0.017 \\
\hline \multicolumn{8}{|l|}{ Primary tumour } \\
\hline \multicolumn{8}{|l|}{ Localisation } \\
\hline right gland & 38 & $(49.4 \%)$ & 26 & $(60.5 \%)$ & 12 & $(35.3 \%)$ & 0.061 \\
\hline left gland & 38 & $(49.4 \%)$ & 17 & (39.5\%) & 21 & $(61.8 \%)$ & \\
\hline both glands & 1 & $(1.3 \%)$ & 0 & $(0.0 \%)$ & 1 & $(2.9 \%)$ & \\
\hline \multicolumn{8}{|l|}{ Diameter } \\
\hline$>10 \mathrm{~cm}$ & 52 & $(67.5 \%)$ & 24 & $(55.8 \%)$ & 28 & $(82.4 \%)$ & $<0.001$ \\
\hline$\leqq 10 \mathrm{~cm}$ & 17 & $(22.1 \%)$ & 16 & $(37.2 \%)$ & 1 & $(2.9 \%)$ & \\
\hline unknown & 5 & $(6.5 \%)$ & 0 & $(0.0 \%)$ & 5 & $(14.7 \%)$ & \\
\hline \multicolumn{8}{|l|}{ Hormon status at presentation } \\
\hline functional & 38 & $(49.4 \%)$ & 21 & $(48.8 \%)$ & 17 & $(50.0 \%)$ & $<0.001$ \\
\hline non-functional & 21 & $(27.3 \%)$ & 15 & (34.9\%) & 6 & $(17.6 \%)$ & \\
\hline unknown & 11 & $(14.3 \%)$ & 0 & $(0.0 \%)$ & 11 & $(32.4 \%)$ & \\
\hline \multicolumn{8}{|l|}{ Liver metastases } \\
\hline Simultaneous liver metastases & 33 & $(42.9 \%)$ & 13 & (30.2\%) & 20 & $(58.8 \%)$ & 0.012 \\
\hline Secondary liver metastases & 44 & $(57.1 \%)$ & 30 & (69.8\%) & 14 & $(41.2 \%)$ & \\
\hline Time between first diagnosis and liver metastases [m] & 43.9 & & 60.5 & & 8.4 & & 0.002 \\
\hline \multicolumn{8}{|l|}{ Number } \\
\hline 1 & 35 & $(45.5 \%)$ & 26 & $(60.5 \%)$ & 9 & $(26.5 \%)$ & $<0.001$ \\
\hline $2-5$ & 12 & $(15.6 \%)$ & 7 & $(16.3 \%)$ & 5 & $(14.7 \%)$ & \\
\hline$>5$ & 20 & $(26.0 \%)$ & 0 & $(0.0 \%)$ & 20 & $(58.8 \%)$ & \\
\hline unknown & 10 & $(13.0 \%)$ & 10 & (23.3\%) & 0 & $(0.0 \%)$ & \\
\hline \multicolumn{8}{|l|}{ Systemic therapies after diagnosis of liver metastases } \\
\hline Mitotane & 43 & (55.8\%) & 21 & (48.8\%) & 22 & $(64.7 \%)$ & 0.164 \\
\hline Chemotherapy & 24 & $(31.2 \%)$ & 8 & (18.6\%) & 16 & $(47.1 \%)$ & 0.007 \\
\hline
\end{tabular}


(32.4\%). 69.8\% of resected liver metastases occurred secondary or metachronous, whereas $58.8 \%$ occurred simultaneous in the non-resection group. There was also a significantly higher percentage of patients with solitary metastases in the resection group. Systemic therapies after the diagnosis of liver metastases like mitotane or other chemotherapies were more often applied in the non-resection group than after resection. Mitotane was used in $64.7 \%$ of patients without liver resection, whereas it was administered after resection in only $48.8 \%$. Other drugs like etoposide, doxorubicin and cisplatin were applied in $47.1 \%$ and $18.1 \%$ respectively (Table 1).

\section{Liver resection for ACC metastases}

In the group of surgical metastasectomy, minor resections of 1 or 2 segments were most frequently performed regardless of a secondary or simultaneous approach (Table 2). Histologically confirmed complete tumour removal (R0 status) was achieved in around 70\% of the cases, with a better performance status when the procedure was done secondarily. Repeated liver resection was carry out in one third of the cases.

\section{Overall and disease free survival}

After liver resection of metastases of adrenocortical origin, the median overall survival was 76.1 months in comparison to 10.1 months in the 34 remaining patients with unresected liver metastases $(p<0.001)$ The 5 -year survival rate was $51.3 \%$ after surgical therapy vs. $10.7 \%$ in the control group without resection. Nevertheless, the disease-free survival after liver resection was only
11.1 months with a 5-year disease free survival rate of 20.1\%. (Fig.2).

\section{Predictive factors}

When comparing the different characteristics between patients in the resection group, only patients with a time interval to the first metastasis/recurrence (TTFR) of greater than 12 months or solitary liver metastases showed significantly prolong survival (Fig. 3, Table 3 ). In the multivariate analysis the hazard ratio continued to be in the same range ( 2.455 and 2.876 respectively), but this was not anymore significant. Neither resection status (R0/R1) nor the extent of liver resection (major/ minor) were significant predictive factors for overall survival. Sex, age, side of primary tumour, size of primary tumour, hormone status or additive mitotane therapy all had no significant influence on overall outcome. Application of chemotherapies other than mitotane within 3 months after liver resection was associated with even poorer survival (Table 3 ). This reflects, however, likely a selection bias, because $50 \%$ of these patients experienced recurrence of ACC within 3 months after liver resection and therefore had a poor prognosis on survival.

Significant predictive factors on the disease-free survival were number of liver metastases, size of primary tumour and chemotherapy after liver resection (Table 4).

\section{Recurrence after liver resection}

Recurrence after the first liver resection of ACC metastases was frequent $(88.4 \%)$ regardless of the timepoint (synchronous or metachronous) of metastatic occurrence. In $57.9 \%$ of cases, recurrence occurred isolated in

Table 2 Liver Resection: Procedural Details

\begin{tabular}{|c|c|c|c|c|}
\hline overall & secondary resection & & simultaneous resection & \\
\hline \multicolumn{5}{|l|}{ Extend of first liver resection } \\
\hline 1 segment & 15 (34.9\%) & 9 & $(30.0 \%)$ & $6(46.2 \%)$ \\
\hline 2 segments & $13(30.2 \%)$ & 8 & $(26.7 \%)$ & $5(38.5 \%)$ \\
\hline mutltiple segments & $1(2.3 \%)$ & 1 & $(3.3 \%)$ & $0(0.0 \%)$ \\
\hline hemihepatectomy & $7(16.3 \%)$ & 6 & $(20.0 \%)$ & $1(7.7 \%)$ \\
\hline extended hemihepatectomy & $3(7.0 \%)$ & 2 & $(6.7 \%)$ & $1(7.7 \%)$ \\
\hline atypical resection & $2(4.7 \%)$ & 2 & $(6.7 \%)$ & $0(0.0 \%)$ \\
\hline unknown & $2(4.7 \%)$ & 2 & $(6.7 \%)$ & $0(0.0 \%)$ \\
\hline \multicolumn{5}{|c|}{ Resection Status of first liver resection } \\
\hline RO & $30(69.8 \%)$ & 23 & $(76.7 \%)$ & $7(53.8 \%)$ \\
\hline R1 & $8(18.6 \%)$ & 5 & $(16.7 \%)$ & $3(23.1 \%)$ \\
\hline Rx & $5(11.6 \%)$ & 2 & $(6.7 \%)$ & $3(23.1 \%)$ \\
\hline \multicolumn{5}{|c|}{ Systemic Therapies after first liver Resection ${ }^{a}$} \\
\hline Mitotane & $21(48.8 \%)$ & 17 & $(56.7 \%)$ & $4(30.8 \%)$ \\
\hline Chemotherapy & $8(18.6 \%)$ & 3 & (10.0\%) & 5 (38.5\%) \\
\hline
\end{tabular}

${ }^{a}$ Application within 3 Months after Liver reseection 
a

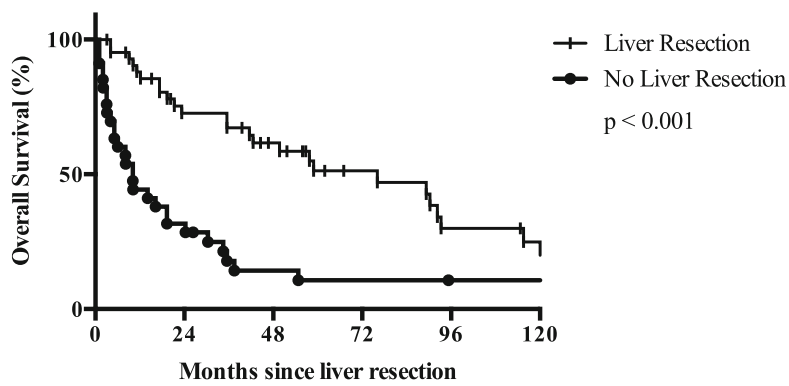

No. at risk

\begin{tabular}{l|llllll} 
Liver resection & 43 & 28 & 21 & 13 & 8 & 6 \\
\hline No liver resection & 34 & 12 & 5 & 4 & 3 & 3
\end{tabular}

b

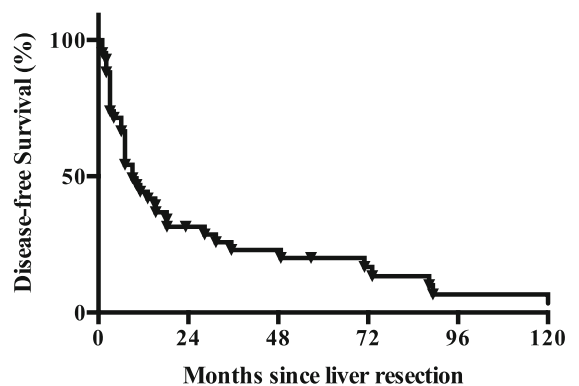

No. at risk

\begin{tabular}{l|llllll} 
Liver resection & 42 & 12 & 9 & 6 & 3 & 3
\end{tabular}

Fig. 2 a Overall survival (OS) after liver resection for ACC liver metastases in comparison to the non-resected group. b Disease-free survival after liver resection

a

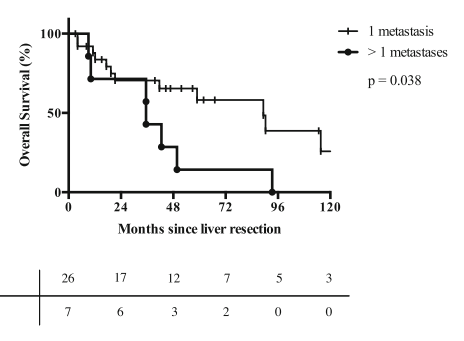

C
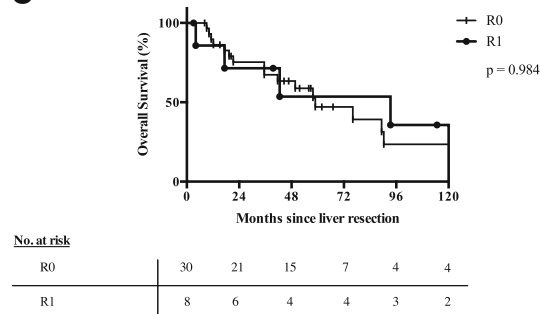

b

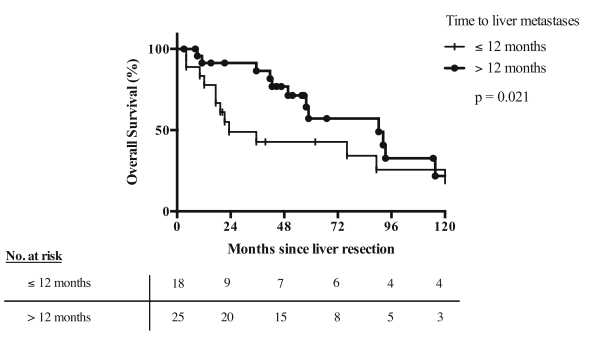

d
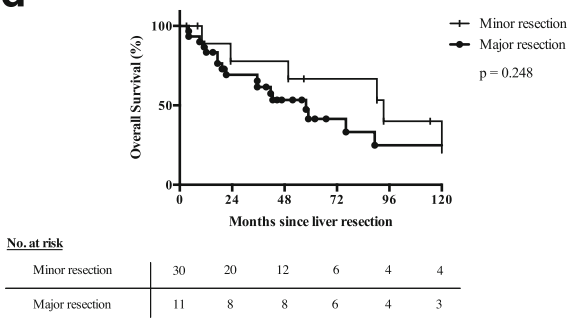

Fig. 3 Overall survival after liver resection of ACC liver metastases for patients with (a) 1 or more metastases, (b) time to recurrence of less or greater than 12 month, (c) R0 and R1 resection and (d) major (>2 segments) or minor liver resection 
Table 3 Predictive factors on overall survival after liver resection

\begin{tabular}{|c|c|c|c|c|c|c|c|c|}
\hline & \multirow[b]{2}{*}{$\mathrm{n}$} & \multirow[b]{2}{*}{ median survival [mo] } & \multicolumn{3}{|c|}{ Univariate analysis } & \multicolumn{3}{|c|}{ Multivariate analysis } \\
\hline & & & $\mathrm{HR}$ & $95 \% \mathrm{Cl}$ & $p$-value & $\mathrm{HR}$ & $95 \% \mathrm{Cl}$ & $p$-value \\
\hline \multicolumn{9}{|l|}{ Sex } \\
\hline female & 30 & 76.1 & 1 & & & & & \\
\hline male & 13 & 58.9 & 1.066 & $0.444-2.563$ & 0.886 & & & \\
\hline \multicolumn{9}{|c|}{ Age at first liver resection (yr) } \\
\hline$\leq 50$ & 13 & 93.3 & 1 & & & & & \\
\hline$>50$ & 30 & 41.6 & 2.225 & $0.830-5.964$ & 0.112 & & & \\
\hline \multicolumn{9}{|c|}{ Occurence of liver metastases } \\
\hline secondary & 30 & 89.3 & 1 & & & & & \\
\hline simultaneous & 13 & 23.3 & 1.485 & $0.673-3.278$ & 0.327 & & & \\
\hline \multicolumn{9}{|c|}{ Major liver resection } \\
\hline no & 30 & 57.8 & 1 & & & & & \\
\hline yes & 11 & 93.3 & 0.580 & $0.226-1.488$ & 0.257 & & & \\
\hline \multicolumn{9}{|c|}{ Number of liver metastases } \\
\hline 1 & 26 & 89.3 & 1 & & & 1 & & \\
\hline$>1$ & 7 & 35.5 & 2.620 & $1.008-6.808$ & 0.048 & 2.455 & $0.888-6.786$ & 0.083 \\
\hline
\end{tabular}

Pathologic margin

$\begin{array}{lll}\text { R0 } & 30 & 58.9 \\ \text { R1 } & 8 & 93.3 \\ \text { Rx } & 5 & 92.3\end{array}$

$\begin{array}{lll}1.037 & 0.372-2.889 & 0.945 \\ 1.127 & 0.401-3.167 & 0.821\end{array}$

Side of primary tumour

right $\quad 26 \quad 76.1$

$\begin{array}{lll}\text { left } & 17 & 89.3\end{array}$

Size of primary tumour $(\mathrm{cm})$

$\begin{array}{lll}\leq 10 & 16 & 92.3 \\ >10 & 24 & 41.6\end{array}$

Secreting primary tumour

$\begin{array}{lll}\text { no } & 15 & 90.3 \\ \text { yes } & 21 & 42.6\end{array}$

Chemotherapy after liver resection

$\begin{array}{lll}\text { no } & 35 & 90.3 \\ \text { yes } & 8 & 17.3\end{array}$

Mitotane after liver resection

$\begin{array}{lll}\text { no } & 22 & 90.3 \\ \text { yes } & 21 & 57.8\end{array}$

Time to liver metastases [mo]

$\begin{array}{lll}>12 & 25 & 90.3 \\ \leq 12 & 18 & 23.3\end{array}$

the liver, followed by lung (28.9\%), abdominal cavity (18.4\%) and bone (7.9\%). Multifocal recurrence occurred in only $10.5 \%$ of all resected cases (4/43). There were only minor differences in the distribution pattern of recurrence between synchronous and metachronous liver metastases (Table 5).

\section{Discussion}

In this retrospective study, we analysed the benefit of surgical resection of isolated ACC liver metastases based on the German ACC registry. Although the registry contained a substantial number of patients with liver metastases of adrenocortical origin, accounting for $29.7 \%$ 
Table 4 Predictive factors on disease-free survival after liver resection

\begin{tabular}{|c|c|c|c|c|c|c|c|c|}
\hline \multirow{3}{*}{\multicolumn{2}{|c|}{$\begin{array}{ll} & \\
& n \\
\text { Sex } & \end{array}$}} & \multirow[b]{2}{*}{ median survival [mo] } & \multicolumn{3}{|c|}{ Univariate analysis } & \multicolumn{3}{|c|}{ Multivariate analysis } \\
\hline & & & $\mathrm{HR}$ & $95 \% \mathrm{Cl}$ & $\overline{p \text {-value }}$ & $\mathrm{HR}$ & $95 \% \mathrm{Cl}$ & $p$-value \\
\hline & & \multicolumn{7}{|c|}{ Sex } \\
\hline female & 30 & 10.2 & 1 & & & & & \\
\hline male & 13 & 7.1 & 1.062 & $0.528-2.136$ & 0.866 & & & \\
\hline \multicolumn{9}{|c|}{ Age at first liver resection (yr) } \\
\hline$\leq 50$ & 13 & 35.5 & 1 & & & & & \\
\hline$>50$ & 30 & 7.1 & 1.552 & $0.759-3.173$ & 0.229 & & & \\
\hline \multicolumn{9}{|c|}{ Occurence of liver metastases } \\
\hline secondary & 30 & 9.1 & 1 & & & & & \\
\hline simultaneous & 13 & 7.1 & 1.309 & $0.640-2.677$ & 0.461 & & & \\
\hline \multicolumn{9}{|c|}{ Major liver resection } \\
\hline no & 30 & 7.1 & 1 & & & & & \\
\hline yes & 11 & 31.4 & 0.558 & 0.256 & 1.216 & 0.142 & & \\
\hline \multicolumn{9}{|c|}{ Number of liver metastases } \\
\hline 1 & 26 & 11.2 & 1 & & & 1 & & \\
\hline$>1$ & 7 & 4.1 & 2.490 & $1.028-6.034$ & 0.043 & 3.747 & $1.292-10.865$ & 0.015 \\
\hline \multicolumn{9}{|c|}{ Pathologic margin } \\
\hline RO & 30 & 10.2 & 1 & & & & & \\
\hline R1 & 8 & 3.1 & 1.859 & $0.827-4.175$ & 0.133 & & & \\
\hline Rx & 5 & 73.1 & 0.809 & $0.276-2.377$ & 0.700 & & & \\
\hline \multicolumn{9}{|c|}{ Side of primary tumour } \\
\hline right & 26 & 7.1 & 1 & & & & & \\
\hline left & 17 & 15.2 & 0.710 & $0.367-1.374$ & 0.309 & & & \\
\hline \multicolumn{9}{|c|}{ Size of primary tumour (cm) } \\
\hline$\leq 10$ & 16 & 18.2 & 1 & & & 1 & & \\
\hline$>10$ & 24 & 7.1 & 2.034 & $0.985-4.198$ & 0.055 & 2.764 & $1.062-7.192$ & 0.037 \\
\hline \multicolumn{9}{|c|}{ Secreting primary tumour } \\
\hline no & 15 & 13.2 & 1 & & & & & \\
\hline yes & 21 & 9.1 & 1.008 & $0.490-2.071$ & 0.983 & & & \\
\hline \multicolumn{9}{|c|}{ Chemotherapy after liver resection } \\
\hline no & 35 & 15.2 & 1 & & & 1 & & \\
\hline yes & 8 & 3.1 & 2.844 & $1.193-6.777$ & 0.018 & 2.568 & $0.936-7.043$ & 0.067 \\
\hline \multicolumn{9}{|c|}{ Mitotane after liver resection } \\
\hline no & 22 & 7.1 & 1 & & & & & \\
\hline yes & 21 & 10.2 & 0.994 & $0.517-1.912$ & 0.985 & & & \\
\hline \multicolumn{9}{|c|}{ Time to liver metastases [mo] } \\
\hline$>12$ & 25 & 18.3 & 1 & & & & & \\
\hline$\leq 12$ & 18 & 6.1 & 1.754 & $0.895-3.436$ & 0.102 & & & \\
\hline
\end{tabular}

(306/1031) of registered patients, only 77 of these patients presented with isolated liver metastases and either received surgical resection or systemic therapies alone.

Irrespective of the number of metastases, our analyses demonstrate a very high 5 -year survival rate of $51.3 \%$ in the 43 liver resected ACC patients. Our data are consistent with previous studies showing similar outcomes after resection of hepatic metastases of ACC origin. In a cohort study of resected non-colorectal and nonneuroendocrine liver metastases of 28 patients with ACC, Adam et al. reported a 5-year overall survival of $66 \%$ and a median survival of 63 months after liver resection [14]. 
Table 5 Recurrence after first Liver resection

\begin{tabular}{llll}
\hline & overall & secondary resection & simultaneous resection \\
\hline Recurrence after first liver resection & $38(88.4 \%)$ & $27(90.0 \%)$ & $11(84.6 \%)$ \\
Median Overall Survival [mo] & 57.8 & 58.9 & 19.3 \\
Median disease-free survival [mo] & 11.1 & 10.2 & 11.2 \\
Localisation of Recurrene & & & $7(63.6 \%)$ \\
Liver & $22(57.9 \%)$ & $15(55.6 \%)$ & $1(9.1 \%)$ \\
Abdomen & $7(18.4 \%)$ & $6(22.2 \%)$ & $4(36.4 \%)$ \\
Lung & $11(28.9 \%)$ & $7(25.9 \%)$ & $1(9.1 \%)$ \\
Bone & $3(7.9 \%)$ & $2(7.4 \%)$ & $2(18.2 \%)$ \\
multiple Localisations & $4(10.5 \%)$ & $2(7.4 \%)$ & \\
\hline
\end{tabular}

Based on these data, ACC patients were ranked as the most favourable group for liver resection after noncolorectal and non-neuroendocrine hepatic metastases by these authors. Based on 19 liver patients with metastatic ACC, Ripley et al. reported a 5 year overall survival of $29 \%$ after resection, and a 5 year overall survival of $29 \%$ patients $(n=5)$ that underwent local hepatic thermoablation (RFA) [15]. Another case report and review of the literature about thermoablation for ACC LM suggested that RFA should be considered as therapy alternative only for patients in whom resection is contraindicated, due to the increased risk of local recurrence in highly vascularized ACC metastases after ablation [16]. Weitz et al. analysed 15 patients with ACC and liver metastases with a 40 months cancer specific survival after resection [17]. A subsequent report from the same institution included 28 patients with ACC LM with a disease-free survival of 7 month and a 5 year survival of 39\% [18]. The latter studies did not exclude patients with extrahepatic tumour manifestation. Thus, the overall outcomes in these studies are reasonably poor compared data obtained from our selected resection group which excluded extrahepatic metastases. Additional data on patients presenting ACC LM suitable for resection but that were never resected is rare or not available in the literature.

Predictive factors to allocate the patient to radical surgery in case of recurrence, seems to be a time to first recurrence (TTFR) of greater than 12 months and a solitary occurrence of liver metastasis. Whereas Erdogan et al. also identified R0 resection as a predictive factor for prolonged overall survival in advanced ACC [9], our data did not show a significant difference between R0 and R1 liver resections. A similar effect was shown for colorectal liver metastases, where patients with R1 hepatic resection achieve similar overall survival rates as R0 resected patients, despite a higher recurrence rate [19]. This fact could be unique in the case of metastasectomy in the liver. However, we have to acknowledge that the number of our study is too small to prove this hypothesis.
Importantly, however, the results of surgical treatment could not be achieved by nonsurgical therapies alone, such as mitotane or other chemotherapies. For mitotane monotherapy in advanced ACC, distinct data about overall survival in patients without resection is difficult to obtain. Some reports indicate tumour response rates of $13 \%$ to $33 \%$ [20]. However, as recently described in the FIRM-ACT trial, even the combination of mitotane with etoposide, doxorubicin and cisplatin (EDP) resulted in an overall survival of only 14.8 month in advanced ACC [21]. In addition, the results of other medical approaches are also of limited or no efficacy [22-27].

Mitotane was shown to have a beneficial effect as adjuvant treatment after radical resection of primary ACC [28]. In our study, we did not observe a significant effect of mitotane in the adjuvant/additive setting after resection of ACC liver metastases. Despite the low number of patients, this result might suggest that adjuvant therapy after metastasectomy of ACC by mitotane or chemotherapy does not appear to be very beneficial. Similarly, in a study of 27 patients with synchronously metastatic ACC Dy et al. observed no apparent impact of chemotherapy after metastasectomy on overall survival. Nevertheless, neoadjuvant chemotherapy in the form of mitotane with or without other chemotherapeutic agents like etoposide, doxorubicin and cisplatin was shown to improve overall survival after resection in 8 patients [29]. Based on these data, neoadjuvant treatment prior to metastasectomy should be considered as a possible pathway in further drafts of trials for stage IV ACC.

In the group of liver resection, the site of primary ACC was more often on the right side (60\%), whereas an equal distribution of the primary ACC to both sides was observed in all 77 patients with isolated liver metastases. Therefore, direct infiltration of the primary tumour into the liver on the right side simulating a solitary metastasis cannot be ruled out for all patients. However, our data suggest that the side of the primary had no significant impact on the overall survival after 
liver resection (see Table 3). So, the matter of direct tumour infiltration can be neglected.

Reliable information about surgical complications in our study collective could not be obtained from the register. However, by looking at the length of hospital stay and a low in-house mortality it can be assumed that the complication rate of ACC liver metastasectomy is similar to resection of other secondary liver tumours like colorectal liver metastases.

Limitations of the study are its retrospective design and the fact that even after excluding 219 patients with liver metastases and extrahepatic manifestation or with incomplete resection, there are still major differences in the basic characteristics between the two groups of resected and non-resected patients, including median age, diameter of the primary tumour or number of metastases that complicate objective comparison of overall survival.

Yet, due to the rareness of ACC and the fact that a large ACC register was the base for this analysis, larger patient collectives than provided in this study with resected isolated ACC liver metastases and an additional corresponding homogenous control group might be hard to achieve.

\section{Conclusions}

Liver resection can achieve long term survival in stage IV ACC with a 5-year survival rate of $51.3 \%$ in this study. However, disease-free survival seems to be short as the median disease-free survival is only 9.1 months despite radical metastasectomy. The main predictive factors for improved outcome appear to be the interval between primary tumour manifestation and hepatic recurrence as well as occurrence of a single versus multiple metastases within the liver.

\section{Abbreviations}

ACC: Adrenocortical carcinoma; ENSAT: European Network for Study of Adrenal Tumours; LM: Liver metastases; OS: Overall survival; RFA: Radiofrequency ablation; TTFR: Time interval to first metastasis/recurrence

\section{Acknowledgements}

We appreciate the support for establishing (Uwe Maeder) and maintaining (Michaela Haaf) the database of the German Adrenocortical Carcinoma Registry.

\section{Funding}

The publication fee for this publication was funded in part by the German Research Foundation (DFG) and the University of Wuerzburg in the funding programme Open Access Publishing.

\section{Availability of data and materials}

Owing to data privacy policy at our facility, publication of patient-related raw data is not possible.

\section{Authors' contributions}

Conception and design: US and JB; analysis and interpretation of Data: JB, US, MF, TJB; acquisition of data: MF, FM, TD, CS, MQ, PN, MK, CTG. All authors prepared, reviewed and gave critical input into each stage of the manuscript. All authors approved the final version of the manuscript.

\section{Ethics approval and consent to participate}

The German Adrenocortical Carcinoma Registry was approved by the ethics committee at the University of Wuerzburg (approval number 86/03), and patients gave written informed consent before enrollment.

\section{Consent for publication}

Not applicable, as no individual patient data has been published.

\section{Competing interests}

The authors declare that they have no competing interests.

\section{Publisher's Note}

Springer Nature remains neutral with regard to jurisdictional claims in published maps and institutional affiliations.

\section{Author details}

${ }^{1}$ Department of General, Visceral, Vascular and Pediatric Surgery, University Hospital, University of Wuerzburg, Wuerzburg, Germany. ${ }^{2}$ Department of Internal Medicine I, Division of Endocrinology and Diabetes, University Hospital, University of Wuerzburg, Wuerzburg, Germany. ${ }^{3}$ Department of Internal Medicine IV - Campus Grosshadern University Hospital of Munich, Ludwig-Maximilians-University Munich, Munich, Germany. ${ }^{4}$ Endocrinology in Charlottenburg, Berlin, Germany. ${ }^{5}$ Department of Medicine I and Clinical Chemistry, University Hospital, University of Heidelberg, Heidelberg, Germany. ${ }^{6}$ Comprehensive Cancer Center Mainfranken, University of Wuerzburg, Wuerzburg, Germany.

Received: 28 May 2017 Accepted: 27 July 2017

Published online: 04 August 2017

\section{References}

1. Kerkhofs TMA, Verhoeven RHA, van der Zwan JM, Dieleman J, Kerstens MN, Links TP, van de Poll-Franse LV, et al. Adrenocortical carcinoma: a populationbased study on incidence and survival in the Netherlands since 1993. Eur J Cancer. 2013:49:2579-86.

2. Fassnacht $M$, Kroiss M, Allolio B. Update in adrenocortical carcinoma. J Clin Endocrinol Metab. 2013;98:4551-64.

3. Else T, Kim AC, Sabolch A, Raymond VM, Kandathil A, Caoili EM, et al. Adrenocortical carcinoma. Endocr Rev. 2014;35:282-326.

4. Varghese J, Habra MA. Update on adrenocortical carcinoma management and future directions. Curr Opin Endocrinol Diabetes Obes. 2017;24:208-14.

5. Fassnacht $M$, Johanssen S, Quinkler M, Bucsky P, Willenberg HS, Beuschlein F, et al. Limited prognostic value of the 2004 International Union against Cancer staging classification for adrenocortical carcinoma: proposal for a revised TNM classification. Cancer. 2009;115:243-50.

6. Reibetanz J, Jurowich C, Erdogan I, Nies C, Rayes N, Dralle H, et al. Impact of lymphadenectomy on the oncologic outcome of patients with adrenocortical carcinoma. Ann Surg. 2012;255:363-9.

7. Berruti A, Baudin E, Gelderblom H, Haak HR, Porpiglia F, Fassnacht M, et al Adrenal cancer: ESMO clinical practice guidelines for diagnosis, treatment and follow-up. Ann Oncol. 2012;23(Suppl 7):vii131-8.

8. Gaujoux S, Mihai R. European Society of Endocrine Surgeons (ESES) and European network for the study of adrenal Tumours (ENSAT) recommendations for the surgical management of adrenocortical carcinoma. Br J Surg. 2017;104:358-76.

9. Erdogan I, Deutschbein T, Jurowich C, Kroiss M, Ronchi C, Quinkler M, et al. The role of surgery in the management of recurrent adrenocortical carcinoma. J Clin Endocrinol Metab. 2013:98:181-91.

10. Simon G, Pattou F, Mirallie E, Lifante JC, Nomine C, Arnault V, et al. Surgery for recurrent adrenocortical carcinoma: a multicenter retrospective study. Surgery. 2017;161:249-56.

11. Adam R, Gramont A de, Figueras J, Guthrie A, Kokudo N, Kunstlinger F, et al. The oncosurgery approach to managing liver metastases from colorectal cancer: a multidisciplinary international consensus. Oncologist 2012;17:1225-1239.

12. Fitzgerald TL, Brinkley J, Banks S, Vohra N, Englert ZP, Zervos EE. The benefits of liver resection for non-colorectal, non-neuroendocrine liver metastases: a systematic review. Langenbeck's Arch Surg. 2014;399:989-1000.

13. Koschker A-C, Fassnacht M, Hahner S, Weismann D, Allolio B. Adrenocortical carcinoma - improving patient care by establishing new structures. Exp Clin Endocrinol Diabetes. 2006;114:45-51. 
14. Adam R, Chiche L, Aloia T, Elias D, Salmon R, Rivoire M, et al. Hepatic resection for noncolorectal nonendocrine liver metastases: analysis of 1,452 patients and development of a prognostic model. Ann Surg. 2006;244:524-35.

15. Ripley RT, Kemp CD, Davis JL, Langan RC, Royal RE, Libutti SK, et al. Liver resection and ablation for metastatic adrenocortical carcinoma. Ann Surg Oncol. 2011;18:1972-9.

16. Bauditz J, Quinkler M, Wermke W. Radiofrequency thermal ablation of hepatic metastases of adrenocortical cancer-a case report and review of the literature. Exp Clin Endocrinol Diabetes. 2009;117:316-9.

17. Weitz J, Blumgart $L H$, Fong $Y$, Jarnagin WR, D'Angelica $M$, Harrison $L E$, et al. Partial hepatectomy for metastases from noncolorectal, nonneuroendocrine carcinoma. Ann Surg. 2005;241:269-76.

18. Gaujoux S, Al-Ahmadie H, Allen PJ, Gonen M, Shia J, D'Angelica M, et al. Resection of adrenocortical carcinoma liver metastasis: is it justified? Ann Surg Oncol. 2012;19:2643-51.

19. Haas RJ de, Wicherts DA, Flores E, Azoulay D, Castaing D, Adam R. R1 resection by necessity for colorectal liver metastases: is it still a contraindication to surgery? Ann Surg 2008;248:626-637.

20. Baudin E, Leboulleux S, Al Ghuzlan A, Chougnet C, Young J, Deandreis D, et al. Therapeutic management of advanced adrenocortical carcinoma: what do we know in 2011? Horm Cancer. 2011;2:363-71.

21. Fassnacht M, Terzolo M, Allolio B, Baudin E, Haak H, Berruti A, et al. Combination chemotherapy in advanced adrenocortical carcinoma. N Engl J Med. 2012;366:2189-97.

22. Sperone P, Ferrero A, Daffara F, Priola A, Zaggia B, Volante M, et al. Gemcitabine plus metronomic 5 -fluorouracil or capecitabine as a second-/third-line chemotherapy in advanced adrenocortical carcinoma: a multicenter phase II study. Endocr Relat Cancer. 2010;17:445-53.

23. Wortmann S, Quinkler M, Ritter C, Kroiss M, Johanssen S, Hahner S, et al. Bevacizumab plus capecitabine as a salvage therapy in advanced adrenocortical carcinoma. Eur J Endocrinol. 2010;162:349-56.

24. Kroiss $M$, Quinkler $M$, Johanssen $S$, van Erp NP, Lankheet N, Pollinger $A$, et al. Sunitinib in refractory adrenocortical carcinoma: a phase II, single-arm, open-label trial. J Clin Endocrinol Metab. 2012;97:3495-503.

25. Berruti A, Sperone P, Ferrero A, Germano A, Ardito A, Priola AM, et al. Phase II study of weekly paclitaxel and sorafenib as second/third-line therapy in patients with adrenocortical carcinoma. Eur J Endocrinol. 2012;166:451-8.

26. Fassnacht M, Berruti A, Baudin E, Demeure MJ, Gilbert J, Haak H, et al. Linsitinib (OSI-906) versus placebo for patients with locally advanced or metastatic adrenocortical carcinoma: a double-blind, randomised, phase 3 study. Lancet Oncol. 2015;16:426-35.

27. Kroiss M, Deutschbein T, Schlotelburg W, Ronchi CL, Neu B, Muller H-H, et al. Salvage treatment of Adrenocortical carcinoma with Trofosfamide. Horm Cancer. 2016;7:211-8.

28. Terzolo M, Angeli A, Fassnacht M, Daffara F, Tauchmanova L, Conton PA, et al. Adjuvant mitotane treatment for adrenocortical carcinoma. N Engl J Med. 2007:356:2372-80.

29. Dy BM, Strajina V, Cayo AK, Richards ML, Farley DR, Grant CS, et al. Surgical resection of synchronously metastatic adrenocortical cancer. Ann Surg Oncol. 2015:22:146-51.

\section{Submit your next manuscript to BioMed Central and we will help you at every step:}

- We accept pre-submission inquiries

- Our selector tool helps you to find the most relevant journal

- We provide round the clock customer support

- Convenient online submission

- Thorough peer review

- Inclusion in PubMed and all major indexing services

- Maximum visibility for your research

Submit your manuscript at www.biomedcentral.com/submit

Biomed Central 